\title{
ELECTRICAL PROPERTIES OF FERROMAGNETIC-INSULATOR NANOCOMPOSITES
}

\author{
Kalinin Yu.E. ${ }^{1}$, Makagonov V.A. ${ }^{1}$, Sitnikov A.V. ${ }^{1}$, Granovsky A.B. ${ }^{2}$ \\ ${ }^{1}$ Voronezh State Technical University, Voronezh, 394026, Moskovskii prospekt 14, Russia \\ ${ }^{2}$ M.V. Lomonosov Moscow State University, Faculty of Physics, Moscow, 119991, Leninskie Gory, 1-2, Russia
}

\begin{abstract}
Analysis of experimental studying of electrical properties of ferromagnetic-insulator nanocomposites is presented in the paper.
\end{abstract}

The investigation of composite materials consisting from ferromagnetic metal nanoparticles distributed in insulating matrix is one of promising directions in the condensed state physics. Scientific interest to the such nanocomposites is caused by the fact that presence of the nanometer-sized ferromagnetic particles leads to appearance of unique electrical, galvanomagnetic, optical and magneto-optical properties. As examples of the most significant properties, we can note the tunneling magnetoresistance reaching $12-13 \%$ at room temperature [1], the giant Hall effect, which is four orders of magnitude greater than the given effect in pure metals [2], the magnetorefractive effect which is two orders of magnitude greater than the traditional magneto-optical effects [3] and others phenomenon [4-5]. This paper is devoted to analysis of our experimental data on the study of electrical properties of ferromagnetic-insulator nanocomposites and the mechanisms of charge carrier transfer established in them.

Various charge carrier transfer mechanisms are realized in ferromagnetic-insulator nanocomposites in pre-percolation region [6]. The first frequently found mechanism is the hopping conductivity via localized states near the Fermi level with a variable hopping range (Mott's model).

In this case the electrical conductivity can be described by the following equation [7]

$$
\sigma=e^{2} \cdot R^{2} \cdot v_{p h} \cdot g\left(E_{F}\right) \cdot \exp \left(-\frac{B}{T}\right)^{1 / 4}
$$

where

$$
B=\frac{16}{a^{3} \cdot k \cdot g\left(E_{F}\right)},
$$

$e$ is the electron charge, $R$ is the hopping length, $v_{p h}$ is the factor of the phonon-phonon interaction spectrum, $T$ is the absolute temperature, $g\left(E_{F}\right)$ is the density of states at the Fermi level, and $a$ is the localization radius of the electron wave function, $\mathrm{k}$ is the Boltzmann's constant.

As an example the temperature dependences of electrical conductivity for $\left(\mathrm{Co}_{45} \mathrm{Fe}_{45} \mathrm{Zr}_{10}\right)_{\mathrm{x}}\left(\mathrm{Al}_{2} \mathrm{O}_{3}\right)_{100-\mathrm{x}}$ composites with different metallic phase concentrations are shown at the fig. 1 in coordinates $\ln \left(\sigma / \sigma_{0}\right) \propto(1 / \mathrm{T})^{1 / 4}$ at the temperature range of $80-180 \mathrm{~K}$. From the data of fig. 1 according eq. 1 it is possible to determine value $B$ for all investigated composites and it allows make estimating the values of effective density of electronic states at the Fermi level. Such estimates for $\left(\mathrm{Co}_{45} \mathrm{Fe}_{45} \mathrm{Zr}_{10}\right)_{\mathrm{x}}\left(\mathrm{Al}_{2} \mathrm{O}_{3}\right)_{100-\mathrm{x}}$ and other composites, are shown on fig. 2.

If we extrapolate the dependence of $g\left(\mathrm{E}_{\mathrm{F}}\right)(\mathrm{X})$ to the concentration of the metal phase corresponding to the percolation threshold, and use the equation

$$
g\left(E_{F}\right)_{X_{C}}=g_{0} \cdot X_{C},
$$

then the $g_{0}$ will give the density of states at the Fermi level of metallic granules (fig. 2), where $g\left(E_{F}\right)_{X_{C}}$ is density of states at the Fermi level, extrapolated to the percolation threshold, $X_{C}-$ percolation threshold.

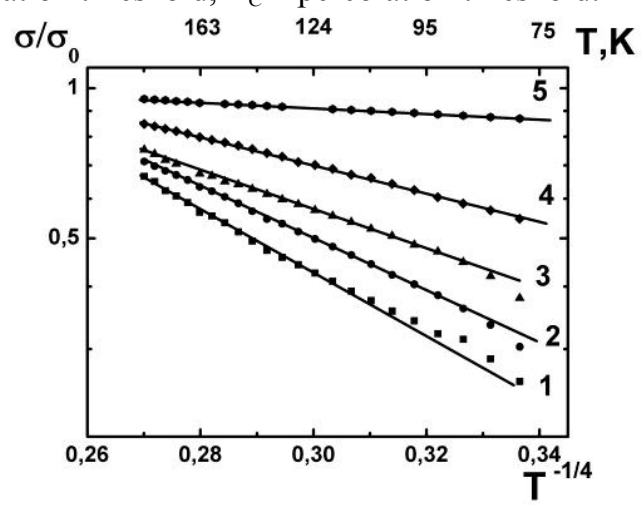

Fig. 1. Temperature dependences of electrical conductivity of $\left(\mathrm{Co}_{45} \mathrm{Fe}_{45} \mathrm{Zr}_{10}\right)_{x}\left(\mathrm{Al}_{2} \mathrm{O}_{3}\right)_{100-\mathrm{x}}$ composites are shown in $\ln \left(\sigma / \sigma_{0}\right) \propto(1 / \mathrm{T})^{1 / 4}$ coordinates, where $\sigma_{0}$ - conductivity at $180 \mathrm{~K}, \mathrm{X}$ - concentration of metallic phase, at.\%: 1-31.7; 2-34; $3-36.3 ; 4-37.3 ; 5-38.7$ 


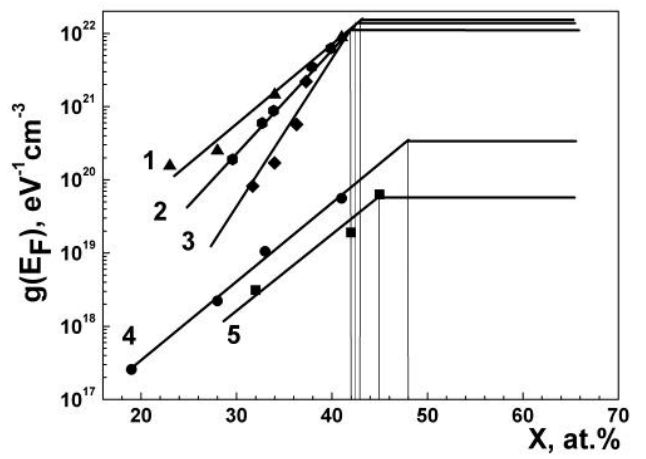

Fig. 2. Dependence of the density of electronic states at the Fermi level from concentration of metallic phase, obtained for nanocomposites $\left(\mathrm{Fe}_{45} \mathrm{Co}_{45} \mathrm{Zr}_{10}\right)_{\mathrm{X}}\left(\mathrm{SiO}_{2}\right)_{100-\mathrm{X}}(1)$, $\left(\mathrm{Co}_{45} \mathrm{Fe}_{45} \mathrm{Zr}_{10}\right)_{\mathrm{X}}\left[\mathrm{Pb}_{0,81} \mathrm{Sr}_{0,04}\left(\mathrm{Na}_{0,5} \mathrm{Bi}_{0,5}\right)_{0,15}\left(\mathrm{Zr}_{0,575} \mathrm{Ti}_{0,425}\right) \mathrm{O}_{3}\right]_{100-\mathrm{X}}(2)$ $\left(\mathrm{Fe}_{45} \mathrm{Co}_{45} \mathrm{Zr}_{10}\right)_{\mathrm{X}}\left(\mathrm{Al}_{2} \mathrm{O}_{3}\right)_{100-\mathrm{X}}(3)$,

$\left(\mathrm{Co}_{41} \mathrm{Fe}_{39} \mathrm{~B}_{20}\right)_{\mathrm{X}}\left(\mathrm{SiO}_{2}\right)_{100-\text { Х }}(4)$ и $\left(\mathrm{Co}_{84} \mathrm{Nb}_{14} \mathrm{Ta}_{2}\right)_{\mathrm{X}}\left(\mathrm{SiO}_{2}\right)_{100-\text { Х }}(5)$

The effective density of electron states at the Fermi level and its derivative with respect to energy estimating from the experimental results showed that the electron density of states at the Fermi level $\left(g\left(E_{F}\right)\right)$ increases in nanocomposites with replacement of material granules according to the following sequence: $\mathrm{CoNbTa} \rightarrow \mathrm{CoFeB} \rightarrow \mathrm{CoFeZr} \rightarrow \mathrm{Co}$ (see fig. 2 ).

The next charge transport mechanism observed in ferromagnetic-insulator nanocomposites is the inelastic resonant tunneling mechanism of electrons via insulator's localized states between granules. The changing of charge transfer mechanism for the studied composites is observed in the temperature range of $\sim 200-300 \mathrm{~K}$. This is expressed in a deviation from the law «1/4» for conductivity. A theoretical model of inelastic tunneling through amorphous dielectric layers was used by the authors $[3,4]$ to explain the temperature dependence of the conductivity of the granular composites located before of the percolation threshold. According to this model, the observed experimental temperature dependences of conductivity are explained by resonant tunneling through a chain of localized states in an amorphous insulating layer in tunnel junctions, and the temperature dependence of the conductivity in a channel containing $\mathrm{n}$ impurities has a power-law form:

$$
\sigma_{n}=P\left(\frac{\Lambda^{2}}{\rho_{0} c^{5}}\right)^{\frac{(n-1)}{(n+1)}} \frac{\left(g a^{2} n^{2} l\right)^{n} T^{\gamma_{n}} E^{\beta_{n}}}{a l} \exp \left[-\frac{2 l}{a(n+1)}\right]
$$

where $a$ is the radius of a localized state, $l$ is the average distance between granules, $\gamma_{n}=n-2 /(n+1)$; $\beta_{n}=2 n /(n+1), P$ is a coefficient, $\Lambda$ - is the deformation potential constant, $\rho_{0}$-density of matrix, $c$-sound velocity, $g$-density of localized states, $E$-depth of occurrence of a localized state in the barrier.

The temperature dependences of the electrical conductivity for $\left(\mathrm{Co}_{45} \mathrm{Fe}_{45} \mathrm{Zr}_{10}\right)_{\mathrm{x}}\left(\mathrm{Al}_{2} \mathrm{O}_{3}\right)_{100 \text {-x }}$ composites with different concentrations of metallic phase are shown in the coordinates $\ln \left(\sigma_{0} / \sigma\right) \propto \mathrm{f}\left[\ln \left(\mathrm{T}_{0} / \mathrm{T}\right)\right]$ (where $\sigma_{0}$ - electrical conductivity at temperature $\left.\mathrm{T}_{0}=300 \mathrm{~K}\right)$ at fig. 3 .

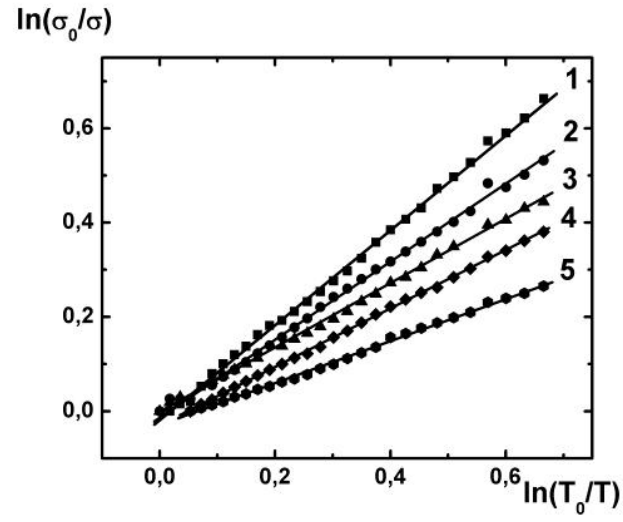

Fig. 3. Temperature dependences of conductivity in model coordinates (eq. 4$)$ for $\left(\mathrm{Co}_{45} \mathrm{Fe}_{45} \mathrm{Zr}_{10}\right)_{\mathrm{x}}\left(\mathrm{Al}_{2} \mathrm{O}_{3}\right)_{100-\mathrm{x}}$ composites with different concentrations of metallic phase $\mathrm{X}$, at.\%: 1 - 31,7; 2 - 34; 3 - 36,3; 4 - 7,3; 5 - 38,7

The analysis of the obtained experimental results showed, that these dependences obey a power law in wide temperature range $(\sim 200-300 \mathrm{~K})$. This allowed us to estimate index $\gamma$ in eq. 4 and make it possible to calculate the average number of localized states $\langle n\rangle$ within tunneling channels between isolated conductive clusters according to the equation

$$
\langle n\rangle=\frac{1}{2}\left[\gamma-1+\left(\gamma^{2}+2 \gamma+9\right)^{1 / 2}\right] \text {. }
$$

The results of calculation showed that with increasing of metal phase concentration, the average number of localized states between the granules decreased, and dependence $\langle n\rangle \propto \mathrm{f}[\mathrm{X}]$ is practically linear (fig. 4).

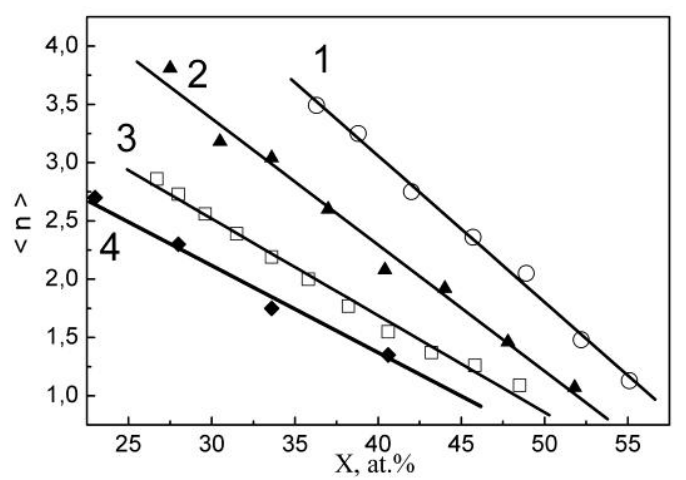

Fig. 4. Dependences of average number of localized states from concentration of metallic phase (X, at.\%) for different composites: $1-\left(\mathrm{Co}_{41} \mathrm{Fe}_{39} \mathrm{~B}_{20}\right)-\mathrm{SiO}_{\mathrm{n}} ; 2-\left(\mathrm{Co}_{86} \mathrm{Ta}_{12} \mathrm{Nb}_{2}\right)-\mathrm{SiO}_{\mathrm{n}}$; $3-\left(\mathrm{Co}_{41} \mathrm{Fe}_{39} \mathrm{~B}_{20}\right)-\mathrm{Al}_{2} \mathrm{O}_{\mathrm{n}}$ and $4-\left(\mathrm{Co}_{45} \mathrm{Fe}_{45} \mathrm{Zr}_{10}\right)-\mathrm{SiO}_{\mathrm{n}}$.

Estimates of average number of localized states within insulator matrix between metal granules, involved into electron transport, made from the experimental results, indicated that it decreases with increasing of heat treatment temperature. The elastic electron tunneling mechanism between granules through a dielectric barrier have been proposed in works $[10,11]$.

Also the thermally activated hopping conductivity between nearest neighboring states or inelastic resonant 
tunneling between granules throughout insulator matrix are obtained in ferromagnetic-insulator nanocomposites. The analysis of the temperature dependences of specific electrical resistance of pre-percolation composites has shown, that there is a deviation from the power law at temperatures above room temperature. At the same time the electrical resistance obey to the exponential law in a wide temperature range, i.e. dependency $\ln \left(\rho / \rho_{\mathrm{o}}\right) \propto \mathrm{f}(1 / \mathrm{T})$ becomes a line, where $\rho_{\mathrm{o}}$ is the specific electrical resistance at $\mathrm{T}=333 \mathrm{~K}$. If we use formula for the thermally activated hopping conductivity to describe the temperature dependences

$$
\rho=\rho_{0} \exp \left(\frac{w}{k T}\right),
$$

where $w$ is being an average hopping energy is of the order of localized states band width, we can obtain the values of $w$ from the slope of dependences $\ln \left(\rho / \rho_{o}\right)$ $\mathrm{f}(1 / \mathrm{T})$. The values of $w$ obtained for some composites are shown in table. 1.

On the other hand, it is also possible to apply the model of inelastic resonant tunneling for this temperature range. The deviation from the power law can be explained by the inclusion of additional channels of tunneling, which leads to an increase in electrical conductivity. In this case, the temperature dependence of the conductivity can be described by the equation

$$
\rho=\rho_{0} \exp \left(\frac{E}{2 k T}\right),
$$

where $E$ is the energy difference between the initial and final states in neighbor granules. The coefficient 2 in the denominator of eq. 7 indicates that energy of the electron can either increase or decrease at inelastic tunneling between the granules.

Table The hopping activation energy (eq. 6) and the energy difference between initial and final states in neighboring granules for inelastic tunneling (eq. 7) for some composites

\begin{tabular}{|c|c|c|}
\hline Composition & $\begin{array}{c}w, \mathrm{eV} \\
\text { (eq. 6) }\end{array}$ & $\begin{array}{c}\mathrm{E}, \mathrm{eV} \\
\text { (eq. 7) }\end{array}$ \\
\hline$\left(\mathrm{Co}_{45} \mathrm{Fe}_{45} \mathrm{Zr}_{10}\right)_{23}\left(\mathrm{Al}_{2} \mathrm{O}_{3}\right)_{77}$ & $0,090 \pm 0,010$ & $0,180 \pm 0,020$ \\
\hline$\left(\mathrm{Co}_{45} \mathrm{Fe}_{45} \mathrm{Zr}_{10}\right)_{28}\left(\mathrm{Al}_{2} \mathrm{O}_{3}\right)_{72}$ & $0,066 \pm 0,007$ & $0,130 \pm 0,014$ \\
\hline$\left(\mathrm{Co}_{45} \mathrm{Fe}_{45} \mathrm{Zr}_{10}\right)_{34}\left(\mathrm{Al}_{2} \mathrm{O}_{3}\right)_{66}$ & $0,030 \pm 0,005$ & $0,060 \pm 0,010$ \\
\hline$\left(\mathrm{Co}_{45} \mathrm{Fe}_{45} \mathrm{Zr}_{10}\right)_{29,6}(\mathrm{PZT})_{70,4}{ }^{*}$ & $0,170 \pm 0,005$ & $0,340 \pm 0,010$ \\
\hline$\left(\mathrm{Co}_{45} \mathrm{Fe}_{45} \mathrm{Zr}_{10}\right)_{33,9}(\mathrm{PZT})_{66,1}{ }^{*}$ & $0,080 \pm 0,007$ & $0,160 \pm 0,014$ \\
\hline$\left(\mathrm{Co}_{45} \mathrm{Fe}_{45} \mathrm{Zr}_{10}\right)_{37,9}(\mathrm{PZT})_{62,1}{ }^{*}$ & $0,050 \pm 0,008$ & $0,100 \pm 0,016$ \\
\hline$\left(\mathrm{Co}_{45} \mathrm{Fe}_{45} \mathrm{Zr}_{10}\right)_{39,9}(\mathrm{PZT})_{60,1}{ }^{*}$ & $0,035 \pm 0,009$ & $0,070 \pm 0,018$ \\
\hline
\end{tabular}

${ }^{*} \mathrm{PZT}-\mathrm{Pb}_{0,81} \mathrm{Sr}_{0,04}\left(\mathrm{Na}_{0,5} \mathrm{Bi}_{0,5}\right)_{0,15}\left(\mathrm{Zr}_{0,575} \mathrm{Ti}_{0,425}\right) \mathrm{O}_{3}$

In composites beyond the percolation threshold, the electrical resistivity is determined by labyrinth structure of conducting channels formed from the metal granules and can have temperature dependence with a temperature coefficient of electrical resistance close to zero. For systems near the percolation threshold, the logarithmic law $\sigma(T)=A(1+\alpha \ln T)$ is satisfied for conductivity, where the parameters $A$ and $\alpha$ depend on concentration of conduction phase. This logarithmic dependence, according to the theory of Efetov et al.[12], is associated with features of the Coulomb interaction in nanogranular material during intergranular tunneling in transition range of concentrations from metallic conductivity to the dielectric regime [7].

At conclusion it should be noted that various charge carrier transfer mechanisms has been observed in ferromagnetic-insulator nanocomposites in prepercolation region.

1. The mechanism of hopping conductivity via localized states near the Fermi level with a variable hopping range according Mott's law.

2. The mechanism of inelastic resonant electron tunneling via insulator's localized states between granules.

3. The elastic electron tunneling mechanism between granules through a dielectric barrier.

4. The thermally activated hopping conductivity between nearest neighboring states or inelastic resonant tunneling between granules throughout insulator matrix.

The electrical resistivity in composites beyond the percolation threshold, is determined by labyrinth structure of conducting channels from metal granules and can have temperature dependence with a temperature coefficient of electrical resistance close to zero.

The work was supported by the Ministry of Education and Science within project part of the state task (project № 3.1867.2017/4.6).

\section{References}

1. A.E. Berkowitz, J.R. Mitchell, M.J. Carey, A.P. Young, S. Zhang, F.E. Spada, F.T. Parker, A. Hutten, G. Thomas. Phys. Rev. Lett. 68 (25), 3745 (1992)

2. B.A. Aronzon, A.B. Granovskii, A.B. Davydov, M.E. Dokukin, Yu.E. Kalinin, S.N. Nikolaev, V.V. Rylkov, A.V. Sitnikov, V.V. Tugushev. JETP 103 (1), 110 (2006)

3. A. Granovskii, V. Gushchin, I. Bykov, A. Kozlov, N. Kobayashi, S. Ohnuma, T. Masumoto, M. Inoue. Phys. Solid State 45 (5), 911 (2003)

4. R.S. Iskhakov, E.A. Denisova, S.V. Komogortsev, L.A. Chekanova, Yu.E. Kalinin, A.V. Sitnikov. Phys. Solid State 52 (11), 2263 (2010)

5. D.A. Filippov, T.A. Galkina, V.M. Laletin, G. Srinivasan. Phys. Solid State 53 (9), 1832 (2011)

6. I.S. Beloborodov, A.V. Lopatin, V.M. Vinokur, K.B. Efetov. Rev.Mod. Phys. 79 (2), 469 (2007)

7. N. Mott and E. Davis, Electronic Processes in Non Crystalline Materials (Clarendon, Oxford, 1971)

8. L.I. Glazman, K.A. Matveev. Sov. Phys. JETP 67 (6), 1276 (1988)

9. L.I. Glazman, R.I. Shehter. Sov. Phys. JETP 67 (1), 163 (1988)

10. B. Abeles, P. Sheng, M.D. Coutts, Y. Arie. Advances in Physics 24 (3), 407 (1975)

11. P. Sheng, B. Abeles, Y. Arie. Phys. Rev. Lett. 31 (1), 44 (1973)

12. K.B. Efetov, A. Tschersich. Phys. Rev. B 67 (17), 174205 (2003)

13. B.I. Shklovskii, A.L. Efros, Electronic Properties of Doped Semiconductors (Springer-Verlag, New York, 1984) 